\title{
Impact of the microstructure of snow on its temperature: A model validation with measurements from Summit, Greenland
}

\author{
R. Dadic, ${ }^{1,2,3}$ M. Schneebeli, ${ }^{2}$ M. Lehning, ${ }^{2}$ M. A. Hutterli, ${ }^{4,5}$ and A. Ohmura ${ }^{3}$
}

Received 1 November 2007; revised 23 January 2008; accepted 13 March 2008; published 18 July 2008.

[1] The influence of snow microstructure on thermal and radiative transfer in snow has not been thoroughly investigated as the tools necessary to efficiently measure microstructural geometry at millimeter resolution have not yet been available. Here we investigate the impact of snow microstructure on the thermal and radiative properties of snow and specifically determine the depth resolution of snow stratigraphy measurements needed to adequately model snow temperatures. To address this subject, detailed information on physical properties of the snow cover was collected at Summit, Greenland, in summer 2003. We present a new set of snow microstructure data,

measured with a high-resolution penetrometer (SnowMicroPen (SMP)). The penetration resistance can be used to estimate the thickness of individual layers but also reflects the thickness and the number of bonds in the snowpack. SMP is a motor-driven, constant speed micropenetrometer acquiring 256 hardness measurements per millimeter. The data were used to describe the physical properties of snow and to compute snow temperatures in the topmost meter of the snowpack using the snow cover model SNOWPACK. The spatial resolution of the snow microstructure and the subsequent parametrization of SMP-estimated density strongly affected the modeled temperature and temperature gradients. The SMP-estimated density was used as an input to SNOWPACK and affected the thermal conductivity and radiative transfer in the snowpack. Our results thus show that highly resolved stratigraphic input data on the order of at least $1 \mathrm{~cm}$ are necessary to adequately simulate snow temperatures and snow metamorphism, including the observed formation of subsurface hoar in the high Arctic snow cover.

Citation: Dadic, R., M. Schneebeli, M. Lehning, M. A. Hutterli, and A. Ohmura (2008), Impact of the microstructure of snow on its temperature: A model validation with measurements from Summit, Greenland, J. Geophys. Res., 113, D14303, doi:10.1029/2007JD009562.

\section{Introduction}

[2] Physical properties of snow have a large impact on snow temperatures, which in turn are an important component of the energy balance in snow-covered areas. The energy balance is key to understanding the reaction of the Greenland ice sheet to a changing global climate and its effects on global sea level. The exchange of energy at the surface of the ice sheet influences the mass balance directly through melt and sublimation and indirectly through glacier dynamics which ultimately controls the

\footnotetext{
${ }^{1}$ Institute of Environmental Engineering, ETH Zurich, Zurich, Switzerland.

${ }^{2}$ WSL Swiss Federal Institute for Snow and Avalanche Research, Davos, Switzerland.

${ }^{3}$ Institute for Atmospheric and Climate Science, ETH Zurich, Zurich, Switzerland

${ }^{4}$ British Antarctic Survey, Cambridge, UK.

${ }^{5}$ Department of Hydrology and Water Resources, University of Arizona, Tucson, Arizona, USA.

Copyright 2008 by the American Geophysical Union. 0148-0227/08/2007JD009562
}

calving rate [Ohmura et al., 1994]. The snow surface creates a special climate in the interior of the ice sheet, where the high elevation further increases the loss of heat because of outgoing radiation [Putnins, 1970]. An up to date description of the energy balance at Summit is in work by Cullen and Steffen [2001] and Cullen et al. [2006].

[3] This study investigates processes which govern the energy fluxes at and below the snow surface and relates them to physical snow properties such as thermal conductivity. The energy balance at the snow surface at Summit is measured. One process, which is still unclear, is the energy flux at shallow depth and how this energy flux would react to changing environmental conditions such as global warming. Furthermore, the presence of snow can greatly perturb the composition of firn air and near-surface polar air [e.g., Dominé and Shepson, 2002]. The physical and photochemical processes leading to the observed uptake or release by snow of a large number of trace gases are to a large degree driven by thermal, optical, and structural (e.g., specific surface area and permeability) properties of snow [Hutterli et al., 1999, 2003; Bottenheim et al., 2002]. Therefore, a detailed knowledge of snow-atmosphere interactions is 
necessary for understanding current atmospheric processes as well as for investigating ice cores, which provide insight in paleoclimates.

[4] Near-surface snow metamorphism is primarily driven by temperature gradients. The temperature in the snowpack is determined not only by the air temperature and shortwave and longwave radiation but also by the thermal conductivity and heat capacity of the snow. Thermal conductivity and heat capacity are not constant throughout the snowpack but vary strongly with changes in snow stratigraphy [Colbeck, 1997]. The temperature of the underlying snow also contributes to determining the temperature in the snowpack.

[5] Only a few investigations attempted to include the dependence of microstructure in thermal conductivity calculations of snow [Sturm et al., 2002]. Arons and Colbeck [1995] conclude that the tools necessary to efficiently measure and parametrize the relevant microstructural geometry have not been available in the past. Several theoretical attempts to predict thermal conductivity on the basis of microgeometry have been made [Adams and Sato, 1993; Arons, 1994], but these have had limited success because of the lack of the necessary geometrical data [Sturm et al., 2002]. It is particularly important to have a quantitative theoretical link between physical snow properties and the textural characteristics. Because snow is a sintered material of ice grains that are thermodynamically unstable, the grains and their interrelationships may change rapidly on timescales of hours to days [Arons and Colbeck, 1995].

[6] Within an ice sheet, thermal energy transfer is dominated by conduction [Brandt and Warren, 1997]. Within the near surface of the snowpack, however, nonconductive processes can include wind-generated ventilation of the snowpack called wind pumping [Colbeck, 1997], latent heat transfer by water vapor migration, convection of air in the pore spaces, and solar radiative heating [Colbeck, 1989b; Albert, 2002; Albert and Hawley, 2002]. Because of their nature, these nonconductive mechanisms are limited to the uppermost meter of the snow where the snow can be highly permeable and affected by penetration of solar radiation.

[7] Investigations of snow stratigraphy on Summit have been mostly focused on relating the physical snow properties to snow chemistry and considering the seasonality in the Greenland snowpack [Dibb and Jaffrezo, 1997; McConnell et al., 1998; Colbeck, 1989b; Hutterli et al., 2003; Albert et al., 2002]. The snow and firn at Summit are a layered system of wind-packed snow that is interspersed with largegrained and hoar layers [Albert and Shultz, 2002]. The hoar layers are formed in the summer [Alley et al., 1990], and by the end of the summer it is common to have multiple hoar layers in the near surface. These sets of hoar layers are identifiable as they age, and indeed, the visual stratigraphy of these layers as a summer marker is one dating technique in firn and ice core analysis through the Holocene and into the glacial transition [Alley et al., 1997]. Alley et al. [1990] suggest that mass redistribution associated with depth-hoar formation can change concentrations of immobile chemicals by as much as a factor of 2 in the hoar layer, altering atmospheric signals prior to archival in ice.

[8] We focused our work on determining the depth resolution of snow stratigraphy measurements needed to adequately model snow temperatures and to investigate the impact of snow microstructure on the thermal properties of snow and therefore on the heat flux within a snowpack. For this, high-resolution snow stratigraphy data were collected using the SnowMicroPen (SMP) [Schneebeli and Johnson, 1998] at Summit, Greenland, in 2003. These data were then used to simulate snow temperatures on the basis of the SNOWPACK model [Bartelt and Lehning, 2002] using different depth resolutions, and the results were compared with measurements.

\section{Methods}

[9] The Greenland Environmental Observatory at Summit $\left(72^{\circ} 35^{\prime} \mathrm{N}, 34^{\circ} 30^{\prime} \mathrm{W}\right)$, Greenland, is a year-round Arctic research station funded by the U.S. National Science Foundation. The station is located in the dry snow zone at the top of the Greenland ice sheet, $3203 \mathrm{~m}$ above sea level, and is nearly $400 \mathrm{~km}$ from the nearest point of vegetated land.

[10] The advantages of this measuring site are the homogeneous snow cover, as there are no topographical effects; a small accumulation rate in summer; the high altitude with clean air; and the availability of meteorological parameters. The yearly snow accumulation rate at Summit is constant at approximately $0.7 \mathrm{~m}(\sim 0.23 \mathrm{~m}$ water equivalent) per year. The climate at Summit can be regarded as representative for a major part of the dry snow zone of the Greenland ice sheet [Ohmura, 2001].

[11] In July 2003, a snow pit ("atm pit") of $2 \mathrm{~m}$ depth was investigated in the vicinity of Summit, Greenland. The snow pit was described by a traditional hand profile, five SMP measurements, and chemical analysis of $\mathrm{H}_{2} \mathrm{O}_{2}$ concentrations in the snowpack. Additional snow pits are described by Dadic [2004]. Continuous measurements of the energy balance components were measured following the standards set by the Baseline Surface Radiation Network [Ohmura et al., 1998].

[12] Using SMP [Schneebeli and Johnson, 1998], we obtained high-resolution snow stratigraphy information. SMP measurements reflect the number and the strength of bonds. The averaged value of penetration resistance over a distance is a gauge of the combined number and strength. These parameters are controlling the thermal conductivity of snow, but they also have a large impact on the radiation penetration through snow. As available parametrizations for calculating the thermal conductivity of snow are mostly based on density, we correlated our high-resolution penetration resistance measurements with traditional density measurements in order to include bond information in the density estimation so that the correlation can be used in any existing relationships between thermal conductivity and density [e.g., Sturm et al., 1997; Adams and Sato, 1993]. From this correlation, it is possible to calculate SMP-estimated densities at any resolution using the penetration resistance.

[13] Snow temperatures were modeled with the snow cover model SNOWPACK using the SMP-estimated density profile generated with the SMP data as initial conditions in the model. Because the heat flux in snow is mainly perpendicular to the layering, changes in thermal conductivity within a single layer have a large impact on thermal conductivity of the whole snowpack. To investigate the effects of snow layering and SMP-estimated density on thermal conductivity, we used different layer thickness 
resolutions of the SMP measurements. SMP data were used to derive bond-weighted density, which was then used to estimate thermal conductivity. This estimated thermal conductivity was used to model snow temperatures. Snow temperatures were calculated at $0.001,0.01$, and $0.1 \mathrm{~m}$ resolution in order to investigate the importance of thin layers. $\mathrm{H}_{2} \mathrm{O}_{2}$ profiles were used to determine summer and winter layers in the snowpack [Hutterli et al., 2004].

\subsection{SnowMicroPen}

[14] The SMP was used to measure the penetration resistance of the snowpack. The SMP is a motor-driven, constant speed snow penetrometer which generates highresolution data, sampling 256 measurements of hardness (penetration resistance) per millimeter. The SMP consists of a small flared measuring tip, $5 \mathrm{~mm}$ in diameter, with a $60^{\circ}$ tip angle. This tip is connected to a high-resolution force transducer which is housed in a drive cone and rod of $16 \mathrm{~mm}$ diameter [Schneebeli et al., 1999]. The drive rod is geared and driven by a constant speed rotary motor [Schneebeli and Johnson, 1998]. The force transducer has a range of $0-500 \mathrm{~N}$ and a resolution of $0.01 \mathrm{~N}$. The penetration velocity used for this work is $20 \mathrm{~mm} \mathrm{~s}^{-1}$. The fundamental idea is that a quasi-continuous recording small-diameter penetrometer will connect more directly to the snow microproperties than large-diameter cone penetrometers do [Johnson and Schneebeli, 1999]. Previous work with the SMP demonstrates its capability of discriminating between different crystal types and different layers [Johnson and Schneebeli, 1999; Schneebeli, 1999; Pielmeier and Schneebeli, 2003]. The SMP profiles we used for this work were $2 \mathrm{~m}$ deep corresponding to the depth of the snow pit. The duration of one profile sampling was $100 \mathrm{~s}$. The entire sampling time for five horizontally repeated measurements, including the handling of the instrument, was around $15 \mathrm{~min}$, whereas the classical snow pit observations took up to $8 \mathrm{~h}$ of work.

\subsection{Snow Temperature Measurements and Snow Pit Observations}

[15] Snow hardness, grain size, and grain shape were measured in all snow pits. Subsurface snow temperatures were measured in each snow pit with a mercury thermometer, but they are not further discussed in this study because the single measurement at different times of the day is not representative for the temperature evolution within the snowpack. Subsurface temperatures were also monitored at high temporal $(5 \mathrm{~min})$ and vertical resolution with thermocouples close to the surface $(0.05,0.1,0.3,0.5,1$, and $1.5 \mathrm{~m})$ and with a thermistor chain deeper down $(0.3$, $0.5,1,2,3,5,10$, and $15 \mathrm{~m}$ ). The snow surface temperature was calculated indirectly in SNOWPACK using the energy balance because the thermocouple situated on the snow surface was heated by the solar radiation and recorded too high temperatures. Measurements at the South Pole [Brandt and Warren, 1993] show that there is a solar-induced $\sim 0.3 \mathrm{~K}$ temperature rise at $4 \mathrm{~cm}$ depth, while at $10 \mathrm{~cm}$ the temperature rise is $\sim 0.18 \mathrm{~K}$. Snow temperatures were measured close to the meteorological tower and not at the location of the pit, which was dug about $5 \mathrm{~km} \mathrm{SSW}$ of the tower. However, given the homogeneous conditions observed in our profiles around Summit (Figure 1), we assume

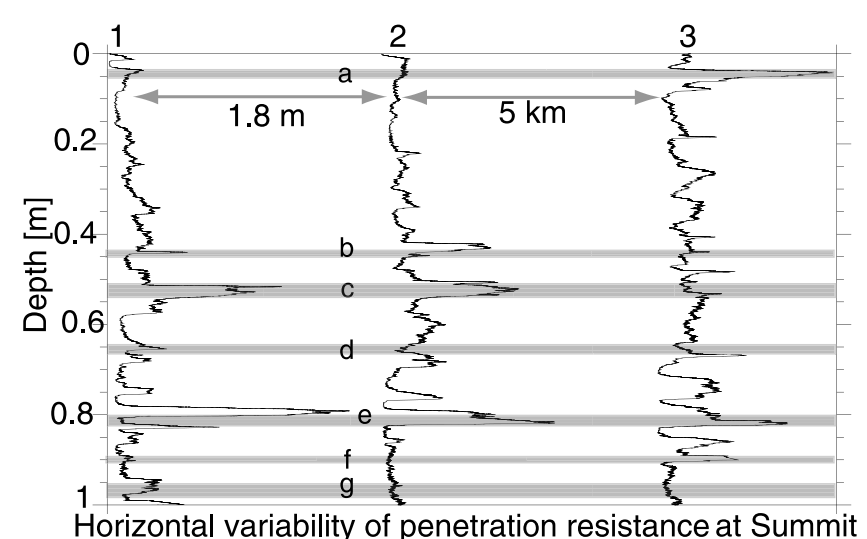

Figure 1. Horizontal variability of the penetration resistance in the atm pit within $1.8 \mathrm{~m}$ and at the location of the snow temperature measurement $5 \mathrm{~km}$ away. The gray bars indicate some of the layers, which have typical markers. Despite the local variability, which exists at the meter scale as well as at the kilometer scale, the dominating features are found at all measurements.

that snow microstructure and temperature were comparable at each site. The small-scale variability within one single snow pit is of the same order as the large-scale variability over several kilometers. Profiles analyzed at a few meters distance showed similar variability as profiles which were located $5 \mathrm{~km}$ apart (Figure 1). Sturm and Benson [2004] examined the continuity of snow layers in both seasonal and perennial snow covers using data from primarily flat locations in Alaska, Antarctica, and Greenland. They found that variance, or heterogeneity in properties, increased up to order of $100 \mathrm{~m}$, then barely increased anymore as the lateral scale was increased to several hundred kilometers. Furthermore, Sturm et al. [2004] show that layer mechanical properties vary over small distances (less than a meter), particularly when the layers in question are thin. Conversely, for thick wind slabs that are the result of significant storm deposition, the lateral continuity of the layer strength over as much as $10 \mathrm{~km}$ is remarkably good.

\subsection{Meteorological Measurements}

[16] In the summer of 2003, the observation program included measurements of temperature and humidity (Vaisala HMP35A), wind speed (Andreraa 2740), and wind direction (Andreraa 2750) at four levels $(0.5,1,2$, and $5 \mathrm{~m}$ ) on a meteorological tower. All radiation instruments were mounted on a solar tracker, allowing direct solar measurements and precise shading of the diffuse incoming radiation instruments. The Kipp and Zonen CH1, CM11, and CM21 instruments are used for incoming/outgoing shortwave radiation, and the CG4 instrument is used for incoming/ outgoing longwave radiation. Synoptical observations, including detailed cloud observations, were made three times a day at 1200,1800 , and 2400 UTC.

\section{4. $\quad \mathrm{H}_{2} \mathrm{O}_{2}$ Concentrations and Density}

[17] Snow samples of a constant volume $\left(69.6 \mathrm{~cm}^{3}\right)$ were collected at a $2 \mathrm{~cm}$ depth resolution with a stainless steel sampling tool and were immediately transferred into airtight, cleaned glass bottles using a high-density polyethyl- 

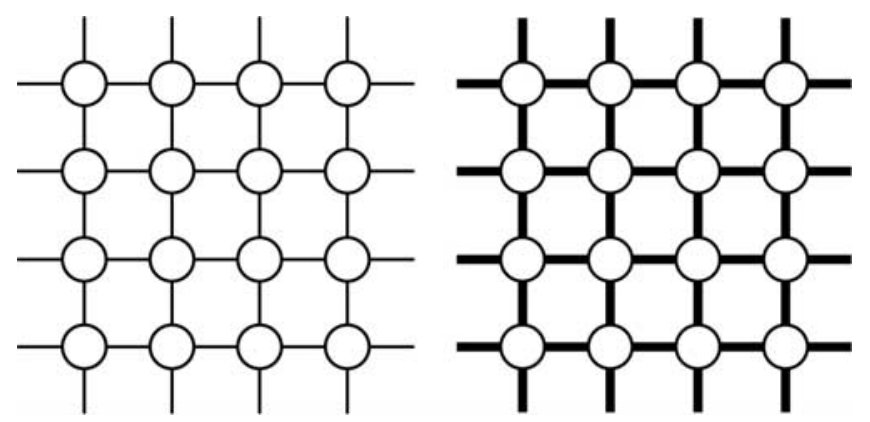

Figure 2. Conceptual model of using SMP-estimated density. The illustration on the right has thicker bonds and therefore has a higher thermal conductivity, even if the density does not change significantly between the two illustrations. SMP measures a combination of the strength and number of bonds and is therefore suitable for parametrization of thermal conductivity.

ene funnel and Teflon-coated spatula. The samples were stored frozen in the dark and were analyzed no more than 2 days after collection and within $2 \mathrm{~h}$ after melting. After raising the $\mathrm{pH}$, the aqueous phase $\mathrm{H}_{2} \mathrm{O}_{2}$ concentrations in the melted snow samples were determined by UV fluorescence spectroscopy after derivatization with 4-ethylphenol in the presence of peroxidase [Hutterli et al., 2004]. The limit of detection, defined as $3 \sigma$, of the baseline was 2 parts per billion by weight, and accuracy was better than $10 \%$.

[18] Snow densities were determined by weighing the sample bottles before and after adding the snow sample. The upper limit of the total uncertainty in density from the sampling procedure and weighing is estimated to be $15 \%$.

\subsection{Derivation of SMP-Estimated Snow Densities From Penetration Resistance}

[19] Arons and Colbeck [1995], Shapiro et al. [1997], and Kaempfer et al. [2005] show that thermal conductivity in snow depends on bond size. Sturm et al. [1997] show that thermal conductivity is correlated with density. However, their measurements also show that there is a large scatter in the density-thermal conductivity relationship. This scatter could be explained by a variable bond thickness in layers with identical density. An increasing density usually causes an increase in bond thickness; however, depending on metamorphism, different bonding can result in identical density [Schneebeli and Sokratov, 2004]. This could also be measured at the profiles (Figure 3). The penetration resistance measured by the SMP is a combination of the strength and number of bonds [Johnson and Schneebeli, 1999]. No direct correlation function or model is currently available to calculate thermal conductivity directly from the penetration resistance of the SMP mainly because thermal conductivity cannot currently be measured at such high resolution. Because most models for thermal conductivity are parametrized as a function of density, and not as a function of number and strength of bonds, another approach was used in this study. We derived a SMP-estimated snow density for parametrization of thermal conductivity, which takes into account the strength of the bonds, using penetration resistance and snow density measurements. The conceptual model of the idea of having a SMP-estimated density is shown in Figure 2. Both illustrations have a similar density, but the right illustration has thicker bonds, which are not heavy and therefore do not change the density significantly but are important in determining thermal conductivity. We therefore think that our approach to include information about strength and number of bonds using SMP data is an enhancement for parametrizations of thermal conductivity, following the idea which was theoretically put forward by Arons and Colbeck [1995].

[20] Thermal conductivities were not measured for this experiment but were numerically modeled with SNOWPACK as a function of SMP-estimated densities and other physical properties of snow such as grain size, bond size, dendricity, and sphericity of snow grains. The latter three were estimated from observed grain shape and grain size using empirical relationships.

[21] Density measurements were correlated to SMP signal in order to increase the spatial resolution of the snowpack using SMP-estimated densities. The highest spatial resolution of density measurements made for this work was $0.02 \mathrm{~m}$, which is low compared to SMP resolution (256 measurements per millimeter). The best fit (Figure 3) found for the available density data and SMP penetration resistance is

$$
{ }^{\prime} \bar{\rho}^{\prime}=283+67 \log (\overline{p R}),
$$

where ${ }^{\prime} \bar{\rho}^{\prime}$ is SMP-estimated density in $\mathrm{kg} \mathrm{m}^{-3}$ and $\overline{p R}$ is the mean penetration resistance (measured SMP value in newtons averaged over $2 \mathrm{~cm}$ ). A logarithmic fit was chosen in order to represent realistic snow densities. A linear fit would generate too high densities for higher penetration resistance values, which are not realistic in a snowpack. The inset in Figure 3 shows that the log value of the penetration resistance has a linear correlation with the density. Data from other snow pits, which are not discussed here, show very similar curves with slope and intercept varying in the range of $10 \%$. With the SMP-density correlation (equation (1)), it is

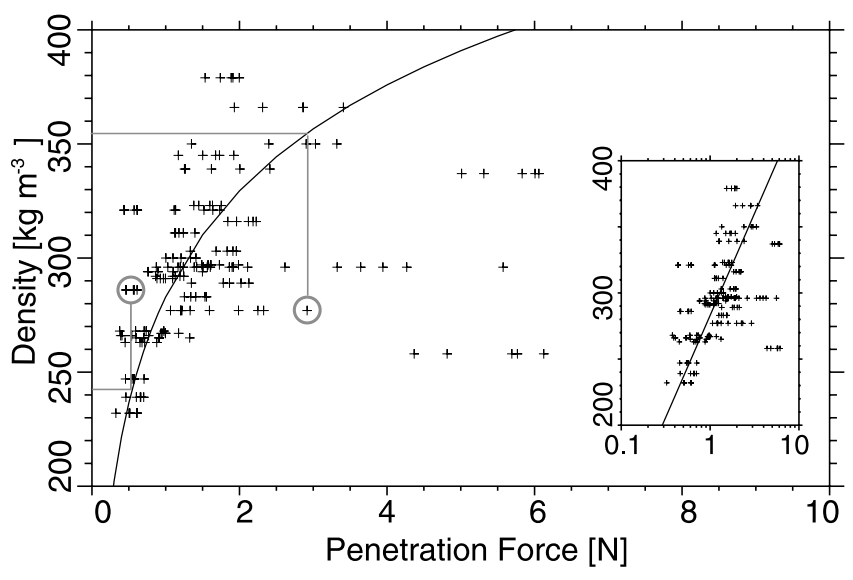

Figure 3. SMP penetration resistance dependence on hand-measured densities for the atm pit. The solid line represents the best fit (equation (1)). The circles show how the SMP values are translated to SMP-estimated density and are used for modeling of thermal conductivities. The inset shows the same data with log linear axis. 
possible to acquire higher SMP-estimated density resolution using penetration resistance measurements and to use it in any existing density-dependent parametrization of thermal conductivity [e.g., Sturm et al., 1997; Adams and Sato, 1993]. The smallest vertical resolution of SMP-estimated density used in this work was $0.001 \mathrm{~m}$, corresponding to 256 penetration resistance values per layer. The penetration resistance is an average value for a given vertical distance in the snowpack. It was also averaged over five horizontally repeated measurements within $1.5 \mathrm{~m}$ of the same pit wall in order to eliminate the effect of the horizontal variability in the snow cover. The horizontal variability is shown in Figure 1 using three selected measurements within $1.8 \mathrm{~m}$ and $5 \mathrm{~km}$. Measurements 1 and 2 were from the atm pit and show the variability within $1.8 \mathrm{~m}$, while measurement 3 was located $5 \mathrm{~km}$ away and was measured 1 day earlier than measurements 1 and 2. The gray bars in Figure 1 indicate some of the layers, which have typical markers. Despite the local variability, which exists at the meter scale as well as at the kilometer scale, the dominating features exist in all three measurements. For example, layers e and b are found at all three locations. Layer $\mathrm{c}$ is found only in measurements 1 and 2, and layer $\mathrm{d}$ is found only in measurements 2 and 3. There might be a vertical shift to these profiles. Only three SMP profiles are shown here, but they show that smallscale variability (measurements 1 and 2 ) is of the similar order as the large-scale variability over several kilometers (measurements 1, 2, and 3). Measurements as close as $0.5 \mathrm{~m}$ show less variability. We are aware of the fact that any snowpack is variable, but we also think that it is possible to partly account for the variability by averaging repeated measurements over a certain distance, at least in a snowpack like that on Summit, where topography does not play a role. In situ measurements at Summit by Dibb and Fahnestock [2004] between 2000 and 2002 show that the variability in accumulation over an $80 \times 80 \mathrm{~m}$ area is $\pm 4.5 \mathrm{~cm} \mathrm{a}^{-1}$ with an accumulation rate of $65 \mathrm{~cm} \mathrm{a}^{-1}$. The same measurements along a $12 \mathrm{~km}$ line to the southwest of the camp show the same accumulation rate, with a somewhat larger variability of $\pm 7 \mathrm{~cm} \mathrm{a}^{-1}$. Similar results of accumulation rates and uncertainties were obtained in previous measurements (1991-1995) $28 \mathrm{~km}$ southwest of the Summit camp.

[22] Figure 3 shows the dependence of penetration resistance on density. The reason for the large scatter in the correlation is that penetration resistance is a function of bonding and microstructure and not only of density. Furthermore, while it was possible with the SMP to account for very thin wind crusts and hoar layers in the snowpack, the density resolution of $0.02 \mathrm{~m}$ did not allow any considerations of such thin layers. Uncertainties in the measured depths on the order of $1 \mathrm{~cm}$, caused by the horizontal variability of the snowpack, potentially also contributed to the scatter in the data. The effect of using SMP data and equation (1) is illustrated in Figure 3. From a physical point of view, this results in thin hard layers given a high thermal conductivity and soft layers (i.e., poorly bonded hoar layers) given a low SMP-estimated density, which converts to a low thermal conductivity. This SMP-estimated density, which is highly dependent on microstructure, can be used to calculate the thermal conductivity of snow with any existing density-dependent parametrization of thermal conductivity [e.g., Sturm et al., 1997; Adams and Sato, 1993].

[23] The hoar layers, which are represented by small penetration resistance values, are poor heat conductors. They are very important for the average heat conductivity in the snowpack. The reason for such a high weighting of the low-conductance layers is because the mean thermal conductivity of a snowpack is not calculated as an averaged value of thermal conductivities over all layers but follows Ohm's law for conductors in series:

$$
\frac{1}{k_{w(\mathrm{tot})}}=\sum_{i=1}^{I} \frac{z_{i}}{Z} \frac{1}{k_{w(i)}},
$$

where $k_{w \text { (tot) }}$ is the mean thermal conductivity for the snowpack, $k_{w(i)}$ is the thermal conductivity in a single layer, $z_{i}$ is the thickness of the layer, and $Z$ is the total snowpack thickness.

\subsection{SNOWPACK}

\subsubsection{Model Applications}

[24] We used SNOWPACK for modeling shallow snow temperatures in the uppermost meter of the snowpack over a 10 day period (first 5 days with clear sky, then overcast) at Summit in July 2003. SNOWPACK is a one-dimensional heat and mass balance model describing the evolution of snow covers on the basis of finite element numerics and includes snow structure and thermal and mechanical properties of snow [Bartelt and Lehning, 2002]. The processes modeled in SNOWPACK are thermal conduction, settling, phase change, water transport, and snow metamorphism. They include consideration of precipitation, shortwave and longwave radiation, sensible and latent heat fluxes, snow transport, and air flow through the topmost layers [Lehning et al., 2002a, 2002b].

[25] As boundary conditions governing the energy exchange on the snow surface, we used the Neumann boundary condition, where the snow surface temperatures are calculated with the following fluxes [Bartelt and Lehning, 2002]:

$$
k \frac{\partial T_{s}}{\partial t}=q_{l w}+q_{s h}+q_{l h}+q_{r r}
$$

where $k$ is thermal conductivity of the uppermost snow layer, $T_{s}$ is the surface temperature, $t$ is time, $q_{l w}$ is the net longwave radiation energy, $q_{s h}$ is the sensible heat exchange, $q_{l h}$ is the latent heat exchange, and $q_{r r}$ is the heat flux from rain, which is zero at Summit. Heat exchange is positive when energy is put into the snowpack and negative when energy is withdrawn. Note that shortwave radiation is treated not as a boundary condition in SNOWPACK but as a volume source of energy for the snow elements close to the snow surface. The amount of radiation absorbed or emitted in an element is determined by solving the radiation transfer equation [Lehning et al., 2002b]. At the layer-element boundaries, the residual radiation is calculated using an extinction coefficient, which varies linearly with density and is therefore highly affected by the SMP-estimated densities. 
[26] Meteorological input parameters for SNOWPACK are air temperature, relative humidity, wind speed and wind direction, incoming and reflected shortwave radiation, incoming and reflected longwave radiation (all measurements at $2 \mathrm{~m}$ above surface), and measured snow temperatures at $1 \mathrm{~m}$ depth as the lower boundary condition. For initialization of the model, we used SMP-estimated densities, classical observations of the snow profile such as grain radius and grain shape, and the snow temperature measured at the initialization time.

\subsubsection{Parametrization of Thermal Conductivity in SNOWPACK}

[27] SNOWPACK uses a thermal conductivity that is not only a function of snow density (in this paper, a function of SMP-estimated density) but makes use of the primary microstructure parameters dendricity, dd (dimensionless); grain size, $r_{g}(\mathrm{~m})$; and bond size, $r_{b}(\mathrm{~m})$. These values are derived from grain shape and grain size estimations in the snow pit, in addition to the primary bulk parameters volumetric fractions of ice, $\theta_{i}$ (dimensionless) (which is calculated with SMP-estimated density), and of water, $\theta_{w}$ (dimensionless). These estimations of primary microstructural parameters and the primary bulk parameters are used for the initialization of the model, and they are changing through time. Conceptually, the conductivity model distinguishes between heat transport in the ice matrix, in the pore space, and in liquid water, which is not relevant at Summit. The heat transport in the pore matrix includes the small transport due to pure conduction in the air and the much larger transport due to vapor transport and phase change at the ice matrix surface. This latter transport is parametrized according to the original conductivity model developed by Adams and Sato [1993]. The original publication of the modified Adams-Sato model [Lehning et al., 2002a] contained two typographical errors: in the two terms for the serial conduction of ice to pore and ice to water the thermal conductivity of pure air, $k_{a}\left(\mathrm{~W} \mathrm{~m} \mathrm{~m}^{-1} \mathrm{~K}^{-1}\right)$, was erroneously used instead of pure ice, $k_{i}\left(\mathrm{~W} \mathrm{~m}^{-1} \mathrm{~K}^{-1}\right)$. In the meantime, a reevaluation of the conductivity formulation was made, and the empirical correction factor, containing four additional empirical parameters [Lehning et al., 2002a, equation (42)], could be replaced by a correction factor containing only two parameters. The correction term describes a transition at densities around $300 \mathrm{~kg} \mathrm{~m}^{-3}$. For higher densities, a different regime results with an overproportionally lower correction, which is used to increase the thermal conductivity. The complete and new formulation of the effective conductivity of snow $\left(k_{e}\right)$ now takes dendricity into account:

$$
\begin{aligned}
\frac{1}{k_{e}}= & \frac{0.13(2-\mathrm{dd})}{\sqrt{\theta_{i}}} \frac{1}{L_{p}} \\
& \cdot\left[\frac{\pi^{2} r_{b} k_{i} N_{3}}{32}+\frac{k_{i} k_{a p} A_{i p}}{L_{i s} k_{a p}+L_{p s} k_{i}}+\frac{k_{i} k_{w} A_{i w}}{L_{i s} k_{w}+L_{w s} k_{i}}+\frac{k_{a p} A_{p}}{L_{p}}\right]
\end{aligned}
$$

[28] In addition to the independent primary parameters explained above, the formulation uses the secondary length scales (m) $L_{p}$ (mean pore length), $L_{i s}$ (ice series length), $L_{p s}$ (pore series length), and $L_{w s}$ (water series length) and crosssectional areas $\left(\mathrm{m}^{2}\right) A_{p}$ (pore cross-sectional area), $A_{i p}$ (cross-sectional area for series conduction in pores), and
$A_{i w}$ (cross-sectional area for series conduction in water), which are all indirectly obtained from the primary parameters. $N_{3}$ is the three-dimensional coordination number, and $k_{a p}\left(\mathrm{~W} \mathrm{~m} \mathrm{~m}^{-1} \mathrm{~K}^{-1}\right)$ is a derived conductivity of the pore space, taking into account vapor phase change and transport. Again, these secondary parameters are derived from the primary parameters. The Clausius-Clapeyron equation is used for the derivation of $k_{a p}$. The derivation of all secondary parameters is described in detail by Lehning et al. [2002a]. The SMP-estimated density, which is derived from the SMP, is used to estimate the volumetric fractions of ice, $\theta_{i}$.

\section{Results}

\subsection{Snow Stratigraphy}

[29] The Summit snowpack showed an interannual layering with large variations in mechanical and thermal properties of snow (e.g., the penetration resistance varies by a factor of 20 within a few centimeters at area A in Figure 4). Most SMP measurements showed a similar pattern (Figure 1), even over larger distances. Typically, there was a thin wind crust on the surface, overlaying a weak layer of subsurface hoar (Figure 4, area B). This layer was not observable in the hand profile (hardness, grain size, and grain shape) that we did in the atm pit, as it was too thin to be seen by the eye.

[30] The wind crust alternating with subsurface hoar is most visible in parts of the deeper snowpack (Figure 4, 0.4$0.8 \mathrm{~m}$ ). Sections with lower penetration resistance can be found in deeper layers as well (Figure 4, area C). The SMP measurements showed much larger variations in the snowpack than the snow properties, which were observed by eye. The hand profile was useful for the interpretation of the penetration resistance values with respect to geometrical information. It confirmed that layers with the lowest penetration resistance consisted of depth hoar. Furthermore, we used the hand profiles to define initial parameters like grain size and grain type in order to run SNOWPACK.

[31] The grain size of the Greenland snowpack showed large variations. There were very small snow grains, which were formed by mechanical destruction of the snow flakes during strong wind conditions, leading to drifting snow. Drifting snow leads to formation of wind crusts, which can be identified with hand measurements of hardness. The grain size of these layers is too small to be determined by eye, and grains become even smaller with the onset of isothermal metamorphism, which reduces surface free energy (surface to volume ratio) to its stable state. However, the snow grains at Summit were not totally rounded even in the deeper layers. The softer layers were mostly composed of larger-faceted grains. The size (diameter) of these grains varied between 3 and $10 \mathrm{~mm}$. Freshly fallen snow was very rarely observed during the field period. On those occasions when snowfall occurred, drifting led to the fracturing and breaking up of the crystals.

[32] Snow density varied between 180 and $440 \mathrm{~kg} \mathrm{~m}^{-3}$ (Figure 4) and showed similar variations throughout the whole snowpack. No measurable densification was observed in the topmost $2 \mathrm{~m}$ of the snowpack toward the bottom; instead, there is an undulating shape of the density profile (Figure 4), which reflects the annual precipitation and metamorphism pattern. Winter layers show a decrease in density 


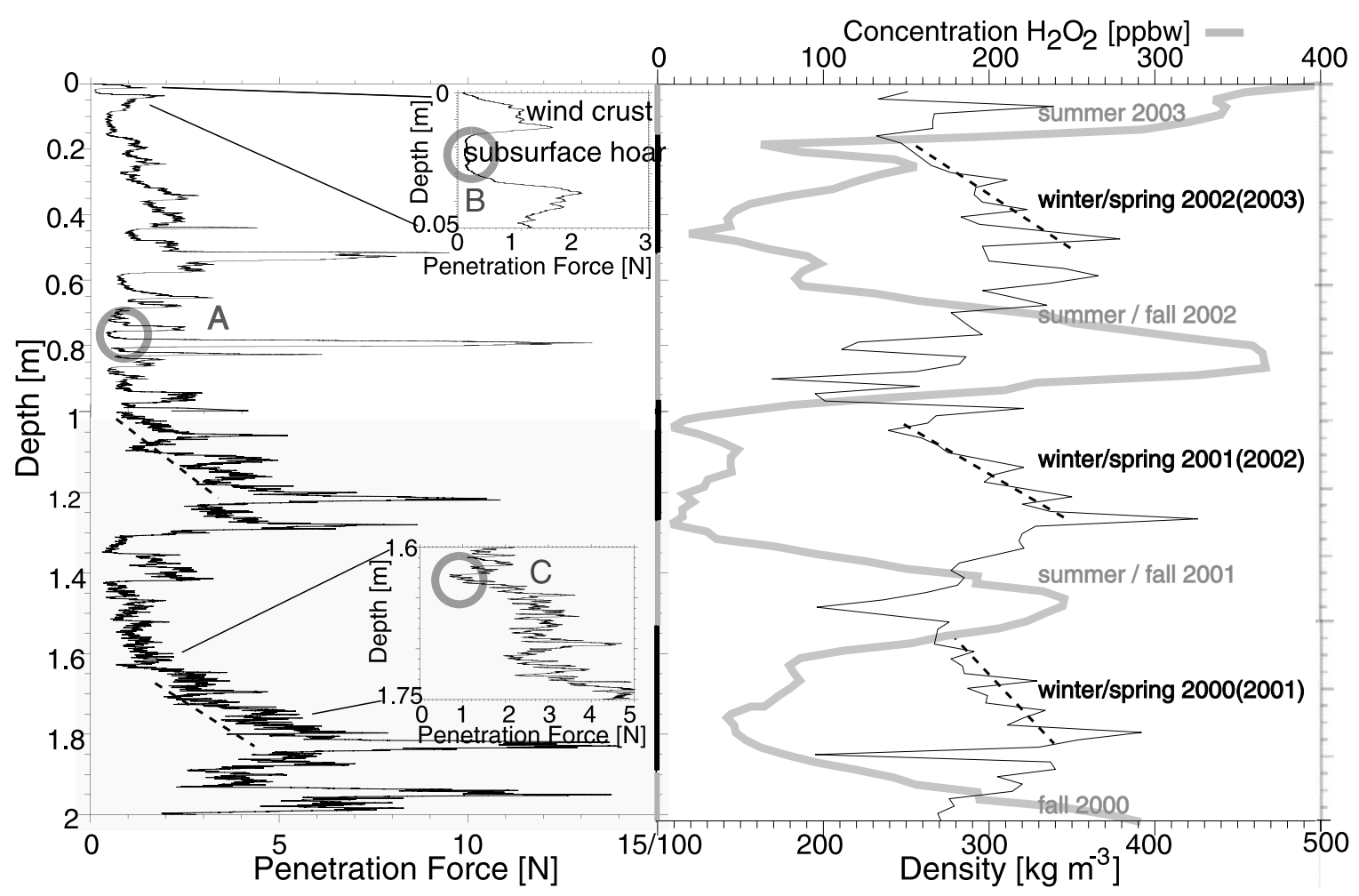

Figure 4. (left) The penetration resistance of the atm pit measured on 8 July 2003 (1 mm running mean). The layers between 0.6 and $0.8 \mathrm{~m}$ (area A) show the weak subsurface hoar (near-surface faceting) layers which alternate with harder wind slabs. These are typical for late summer and fall months. The insets show a detailed penetration resistance at the snow surface (area B) and in the winter layering of the deeper snowpack (area C). (right) Density (black line) and $\mathrm{H}_{2} \mathrm{O}_{2}$ (gray line) against snow depth are shown. Distinguishing between seasons is based on $\mathrm{H}_{2} \mathrm{O}_{2}$ concentrations. The dashed lines indicate densification of winter layers and bond hardening.

toward spring (Figure 4, dashed lines), while summer layers show an increase in density toward fall. Similar density profiles are found in the work by Albert and Shultz [2002], where they show that the density profile of the top $3 \mathrm{~m}$ reveals the annual cycle in snow types, the low-density areas being deposited in the previous summers, while the higher-density wind pack is characteristic of winter snowpack [Albert and Shultz, 2002]. Density trends are not entirely reflected in penetration resistance. Albert and Shultz [2002] also observe that in the top $3 \mathrm{~m}$, metamorphism clearly has a much greater impact on grain size and permeability than on density. A hardening of the bonds toward the bottom was observed, which is strongly reflected in increasing penetration resistance with depth for winter 2000-2001 but is not reflected in penetration resistance values of the most recent winter, 2002-2003.

[33] The high-density layers represent the winter snowpack, and the layers with lower densities (hoar layers) represent the summer-fall snowpack. The dating was based on the $\mathrm{H}_{2} \mathrm{O}_{2}$ concentrations, which are high during the summer months [Hutterli et al., 2004].

\subsection{High-Resolution Thermal Conductivity and Snow Temperatures}

[34] For the calculations of thermal conductivity with different vertical resolutions of the snowpack, the SMP data were averaged over different vertical distances $(1,10$, and
$100 \mathrm{~mm}$ ) in order to obtain different resolutions of SMPestimated densities (equation (1)). With these densities as input, the thermal conductivities, as well as the radiation penetration through snow, were calculated in SNOWPACK (equation (4)). Figure 5 shows time series of calculated snow temperatures. The temperatures, as well as the penetration depth of the daily temperature cycle, are highly overestimated for the low-resolution model. The penetration depth in the high-resolution model is about $50 \mathrm{~cm}$ and is much better at representing measured values. An analysis from the measured snow temperatures at Summit shows that the penetration depth of daily temperature variations can be observed down to $50 \mathrm{~cm}$ on clear-sky days and down to $30 \mathrm{~cm}$ on cloudy days [Dadic, 2004]. Figure 6 shows a time series of modeled local temperature gradients in the Summit snowpack for low resolution (100 mm) (top) and for high resolution $(1 \mathrm{~mm})$ (bottom). The temperature gradients in the low-resolution model are very high throughout the whole snowpack, and they get highly negative in the uppermost part. The high-resolution model has more realistic local temperature gradients and snow temperatures and shows a much more complex pattern in the top few centimeters of the snowpack, which indicates changing snow metamorphism patterns. Grain and bond size are not discussed here, but they are slightly increasing during the 10 day modeling period for both models. 

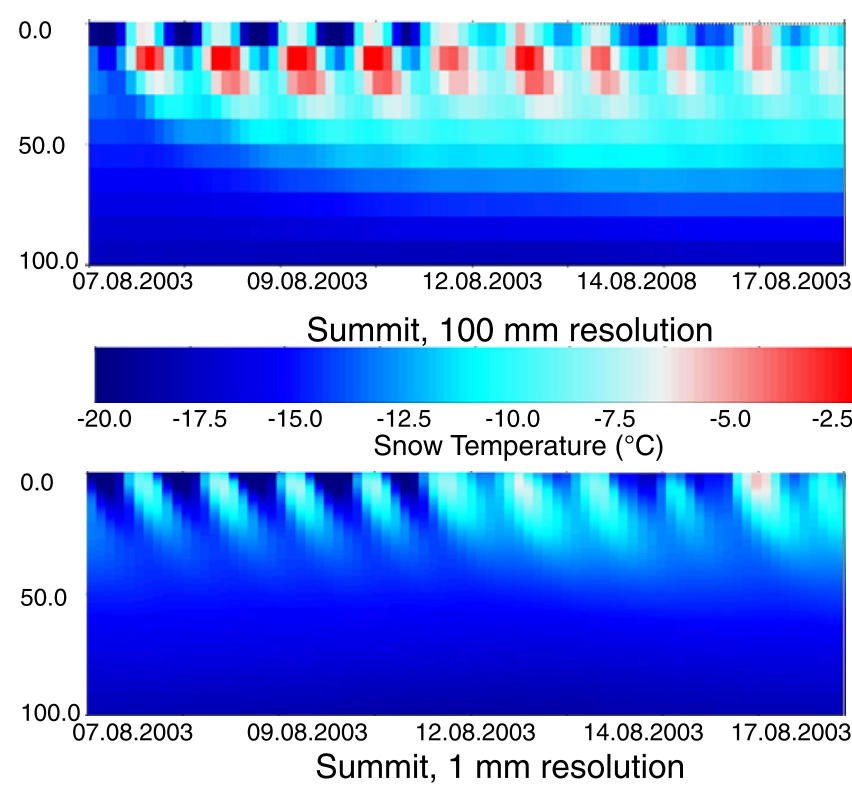

Figure 5. Time series of modeled snow temperatures for (top) low resolution (100 $\mathrm{mm}$ ) and (bottom) high resolution (1 mm). The temperatures are much higher for the lowresolution model run and are highly overestimated. The penetration depth of the daily temperature cycle is overestimated in the low-resolution model as well.

[35] Figure 7 shows modeled and measured snow temperatures for 100 and $300 \mathrm{~mm}$ depth with SMP resolutions of 100 and $1 \mathrm{~mm}$. At low resolution, the model overestimated snow temperatures by up to $8^{\circ} \mathrm{C}$ during daytime at $100 \mathrm{~mm}$ depth and by even more at $300 \mathrm{~mm}$ depth. At high resolution, the modeled values agreed within a few degrees with the measurements (Figure 7) but remained too high for the $300 \mathrm{~mm}$ depth throughout the whole simulation. The discrepancies in modeled and measured temperatures are smaller on overcast days (days 194-198), especially for the higher-resolution simulation. The $10 \mathrm{~mm}$ resolution shows similar results to the $1 \mathrm{~mm}$ resolution and is therefore not discussed separately. One of the reasons for the similarity of the 10 and $1 \mathrm{~mm}$ results might be because SNOWPACK merges layers that are alike together, so the $1 \mathrm{~mm}$ model output did not have 1000 layers but had only around 300 . Thus, we conclude that the important scale for the studied snowpack is of the order of $10 \mathrm{~mm}$ but might be different for other snowpacks. The temperatures modeled with low resolution peak earlier than the measured temperatures and show amplitudes which are too large for a given depth, suggesting that either the radiation penetration is overestimated by not resolving the wind crusts, which damp the radiation penetration, or thin hoar layers, which act as thermal breaks, are not properly resolved.

\section{Discussion}

\subsection{Snow Stratigraphy}

[36] A similar pattern of the SMP signal was observed for all snow pits that were investigated during the field season. One of the most outstanding patterns observed in the snowpack was the alternation of soft hoar layers and harder wind slabs. The latter originated from very windy periods without large amounts of precipitation, typically observed in fall [Albert and Shultz, 2002; Alley et al., 1990]. Strongly faceted crystals (hoar) occur in the uppermost layers of polar ice sheets, where they have long been associated with "firn quakes," a sudden collapse of subsurface hoar layer which is detectable over some distance. Most of the growth of these layers occurs in late summer because of the coincidence of higher temperatures and higher temperature gradients [Colbeck, 1989b] and shows a decrease in specific surface area. In the Summit snowpack, faceting persisted throughout the whole profile, either remaining from the original shape of faceted grains or occurring because of ongoing temperature gradient metamorphism. The existence of these low penetration resistance layers lead us to conclude that these layers are not affected much by the overburden pressure at these depths.

[37] Our interpretation of these observations is that vapor diffusion sintering is the dominant process. Vapor diffusion sintering is known to not cause a densification of the porous sintering material [German, 1996]. At the same time, the viscosity of the ice and the overburden pressure are too small to cause densification over the whole profile. Indirectly, this is also a hint that the other volume sintering processes causing densification (grain boundary diffusion and surface diffusion) are small compared to vapor diffusion. This also means that porosity remains constant. Temperature gradient metamorphism increases bond and grain size; however, the number of bonds per volume decreases. According to the experiments presented by Schneebeli and Sokratov [2004], this results in a higher thermal conductivity and indicates an increased thermal

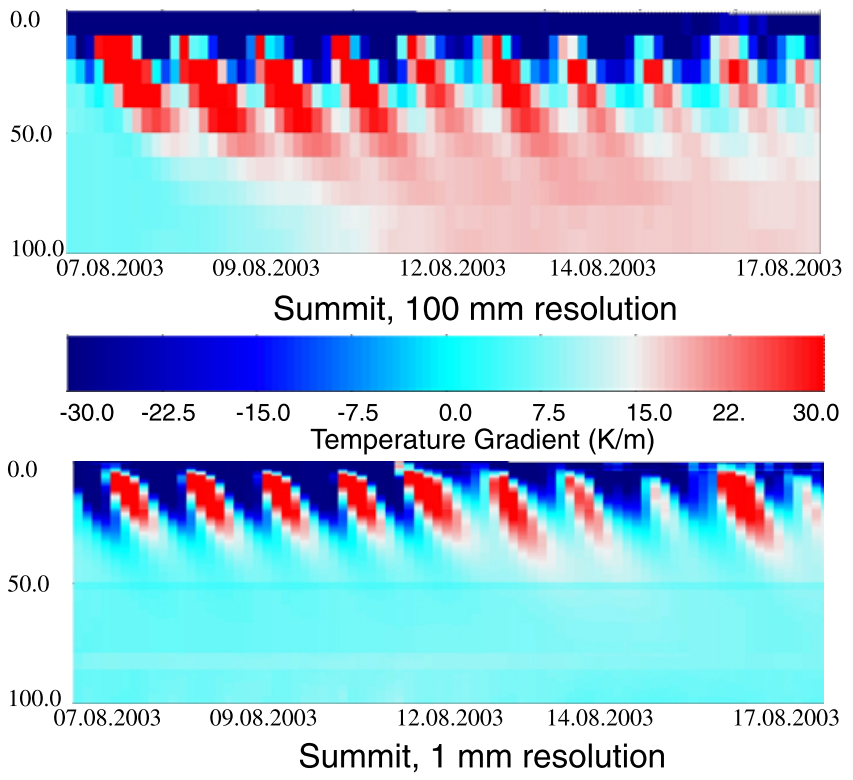

Figure 6. Time series of modeled local temperature gradients in the Summit snowpack for (top) low resolution $(100 \mathrm{~mm})$ and (bottom) high resolution $(1 \mathrm{~mm})$. The temperature gradients in the low-resolution model are overestimated in the whole snowpack. The high-resolution model shows larger changes in the local temperature gradients through time and a complex pattern of temperature gradients in the topmost centimeters. 


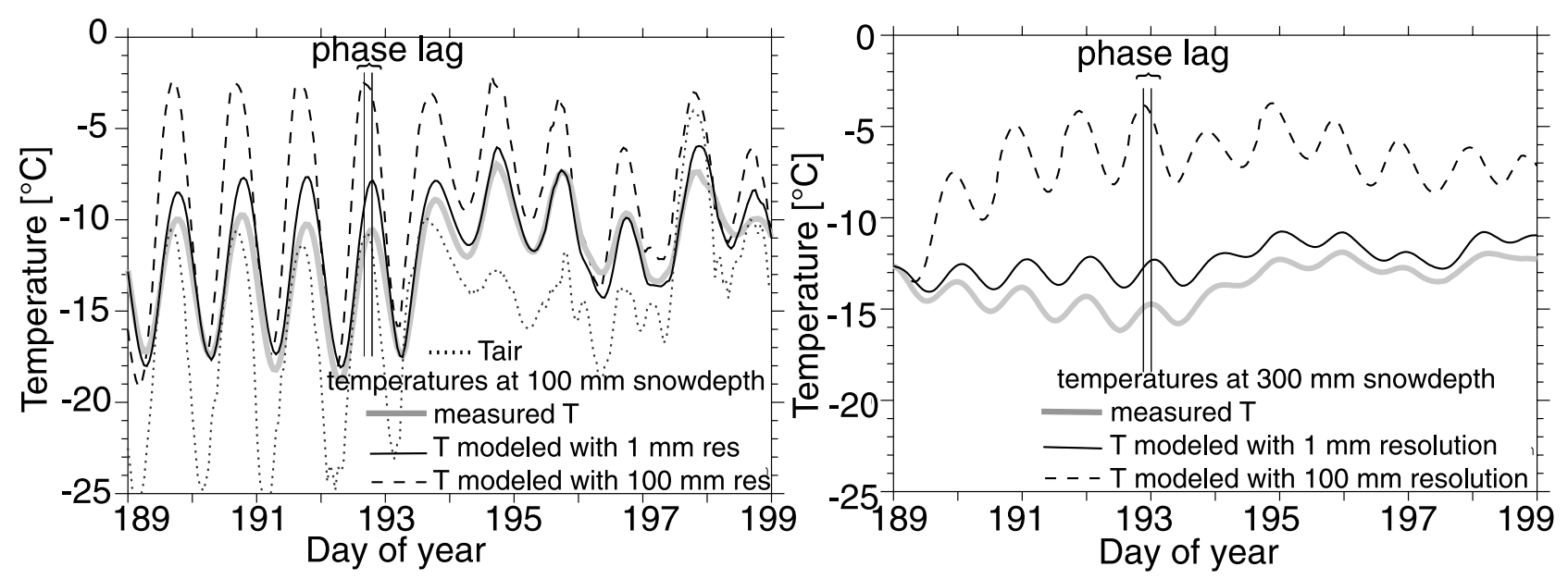

Figure 7. Modeled and measured temperatures over a 10 day period (clear sky for days 189-193 and overcast for the rest of the time) for two different depths. The dotted line is the measured air temperature. The dashed line is the modeled temperature computed with a resolution of $100 \mathrm{~mm}$, and the solid black line is the modeled temperature computed with a resolution of $1 \mathrm{~mm}$. The thick gray line is the measured temperature for the same depth. The $10 \mathrm{~mm}$ resolution shows similar results as the $1 \mathrm{~mm}$ resolution and is not plotted here. The $100 \mathrm{~mm}$ model overestimates snow temperatures and their amplitudes and does not consider the low-conductivity layers or the high-density winds slabs (which are important for radiation penetration), which are not sampled at low resolution. The vertical lines indicate the phase lag between the low-resolution model results and measured temperatures.

conduction for older snow without an increase in density. The highest and lowest density values of the three winters represented in the observed profile do not change significantly, and an overall densification trend is not visible. The interannual variability, which is reflected throughout the whole density profile, is not reflected entirely in the whole profile of penetration resistance but only in winter-spring layers, which were older than 1 year (Figure 4, dashed lines in penetration resistance plot). In these older winter layers, we find larger homogeneous layers whose penetration resistance increased with increasing depth (Figure 4, e.g., 1.6-1.8 m). The spring-summer transition (e.g., 1.2 and $1.8 \mathrm{~m}$ ) which creates hard layers is always highly visible, and the amplitude between the hard spring-summer transition and the soft fall-winter transition (e.g., 1.4-1.6 m) seems to be increasing over time, which means that harder layers harden much more than softer layers do, showing lower amplitudes with increasing depth in the high-frequency signal. We cannot entirely explain this, but we think that the topmost $2 \mathrm{~m}$ of the snowpack are affected by temperature gradient fluctuations caused by seasonal and multiannual temperature fluctuations. The yearly swings in temperature cause temperature gradients that drive snow and firn metamorphism [Colbeck, 1989a], especially in the top several meters. This process, which is discussed above as vapor diffusion sintering, keeps the density unchanged down to the depth where the overburden pressure becomes dominant, which means that there is no observable densification of the whole snowpack occurring in the top of the snowpack. Albert and Shultz [2002] also observe in their data that in the top $3 \mathrm{~m}$, metamorphism clearly has a much greater impact on grain size and permeability than on density. The increase of bond strength without a change in density during temperature gradient metamorphism was also observed in a laboratory experiment reported by Schneebeli et al. [1999].
Deriving thermal conductivity from the density profile in Figure 4 would only lead to an undulating thermal conductivity with depth, while deriving it from the penetration resistance generates a more variable thermal conductivity, which reflects the thickening of the bonds, and a respective increase in hardness.

\subsection{High-Resolution Thermal Conductivity and Snow Temperatures}

[38] Figures 5 and 6 show the strong impact of the vertical resolution of penetration resistance on calculated temperature gradients. The temperatures modeled at low resolution showed much larger amplitudes than the measured temperatures or the temperatures modeled with high resolution, which leads us to the conclusion that the damping of the temperature with depth was not represented correctly with low-resolution inputs. This may be caused by overestimating the penetration of shortwave radiation as well as thermal conductivity of the snowpack when using low-resolution data as input. With this input, neither thin wind crusts, which reduce penetration of solar radiation, nor subsurface hoar layers, which act as thermal insulators, are well represented. The radiation effect is much smaller for cloudy days (days 194-199), which decreases the discrepancies in modeled and measured temperatures on overcast days (days 194-198) and suggests that the absorption of solar radiation is overestimated in the model run with lowresolution input to a much higher degree than in the model run with high-resolution input. If the discrepancy in measured and modeled temperatures at $300 \mathrm{~mm}$ was caused only by radiation absorption, it should be negligible during nighttime and overcast days, when the shortwave incoming radiation was small. However, the error for the $300 \mathrm{~mm}$ temperature remains very high for the low-resolution model run throughout the modeled period and therefore must be at 
least partly caused by thermal conduction. The results agree much better with measurements for the high-resolution model run. The effect of overestimated thermal conductivity at low-resolution results is further visible in underestimated phase lag (Figure 7). The fact that the temperatures modeled at low resolution peaked earlier than the measured ones indicated that the modeled temperatures reacted too fast to the daily temperature cycle, and the phase lag was not represented correctly. This is likely due to a combination of overestimating both thermal conductivities and radiative transfer into the snowpack. Radiative transfer is also highly influenced by physical snow properties such as thin windpressed layers, consisting of very small particles and correspondingly high reflectance, which prevent radiation from penetrating into the snowpack, are not adequately represented at low resolutions. We think that subsurface hoar layers, especially the one at $5 \mathrm{~cm}$ depth (Figure 4, area B), cause a large jump toward lower thermal conductivity and therefore act as thermal breaks that are not represented when measured density is only used to derive thermal conductivity. Near-surface snow temperatures were not reproduced well at low vertical resolution. This resulted in poor representation of very thin layers like wind crusts or hoar layers, which play an important role for thermal conduction (equation (2)) as well as for the radiative heat flux at Summit. This points to a strong feedback between smallscale snow structure, temperature, and temperature gradients in snow, which in turn are driving the metamorphic processes affecting the snow microstructure. The formation of subsurface hoar layers (near-surface faceting) is such a process, which only occurs where large local temperature gradients exist.

[39] The spatial variability in the layering of the snowpack could also be responsible for at least parts of the differences between the modeled temperatures at the snow pit and the thermocouple chain measurements at the meteorological tower. Solar heating of the thermocouples could be a potential source of error but is shown to be rather small in the depth of $10 \mathrm{~cm}(\sim 0.18 \mathrm{~K}$ [Brandt and Warren, 1993]) compared to the temperature differences we are looking at. The uncertainty of our parametrization will lead to a systematic overestimation or underestimation of the temperature. In any case, fine spatial resolution of thin layers is very important for the simulation of snow temperatures, seeing that temperature gradients are the most important driving force for metamorphism. In this sense, a high spatial resolution is necessary not only at the surface but throughout the entire snowpack, as shown in Figure 6.

\section{Conclusions}

[40] Shallow snow layers at Summit were investigated with several methods. The traditional hand profile method was complemented by a high-resolution SnowMicroPen. The SMP data showed a complex stratification in the Summit snowpack, which could not be acquired with the hand profile. The data were also used to investigate the importance of thin, near-surface snow layers when modeling snow temperatures. For this purpose, the SMP data were averaged over different vertical distances (1, 10, and $100 \mathrm{~mm}$ ). A large difference in thermal conductivities and modeled temperatures was observed when calculating snow temperatures using different vertical resolutions. Using higher resolution of the snowpack resulted in larger temperature gradients, which are responsible for formation of near-surface faceting (subsurface hoar). The temperatures modeled at higher resolutions (1 and $10 \mathrm{~mm}$ ) showed significantly better agreement with measured temperatures than the ones at lower $(100 \mathrm{~mm})$ resolution, which resulted in far too high temperatures, because of poorly represented thermal properties and radiation penetration. Thus, modeling snow temperatures without accounting for thin layers overestimated radiation penetration (by not accounting for thin wind crusts, which decrease radiation penetration into the snowpack) and thermal conductivity (by not accounting for thin subsurface hoar layers, which decrease thermal conductivity because of their insulating properties). Both effects lead to overestimation of snow temperatures as well as to a phase shift in the daily temperature cycle because of underestimated phase lag. Our results thus show that the SMP is a tool that can efficiently evaluate snow microstructure and improve input to snow energy balance models and that thin layers are very important in snowpack heat transfer. Furthermore, we conclude that there is a strong feedback between small-scale snow structure and snow temperature, which is driving the physical and possibly the chemical processes in the snowpack. The recommended resolution for Arctic snowpacks is of the order of $10 \mathrm{~mm}$ but might differ slightly for other locations with different snowpacks. Considering the importance of thermal conductivity as well as the importance of radiation penetration for the simulation of the snowpack and the surface energy balance, the uncertainties in the presented parametrization require more detailed measurements in the future. Future studies should aim at correlating SMP data directly with high-resolution measurements of thermal conductivity and radiation penetration. This could make the SMP a very efficient tool not only for measuring mechanical properties but also potentially for acquiring thermal conductivity of snow at the high resolution needed for snowpack models.

[41] Acknowledgments. We would like to acknowledge the help of S. Bourgeois, K. Schroff, H. J. Frey, J. F. Burkhart, D. K. Friel, D. Belle-Oudry, T. Kaempfer, and VECO Polar Resources for their support. We thank R. Brandt, two anonymous reviewers, and the scientific editor J. Austin for their valuable comments and suggestions. This work was made possible by the Swiss NSF with grant 200020-103558 and with the U.S. NSF grant OPP-0221150.

\section{References}

Adams, E. E., and A. Sato (1993), Model for effective conductivity of dry snow cover composed of uniform spheres, Ann. Glaciol., 18, 300-304. Albert, M. R. (2002), Effects of snow and firn ventilation on sublimation rates, Ann. Glaciol., 35, 52-56.

Albert, M. R., and R. L. Hawley (2002), Seasonal changes in snow surface roughness characteristics at Summit, Greenland: Implications for snow and firn ventilation, Ann. Glaciol., 35, 510-514.

Albert, M. R., and E. F. Shultz (2002), Snow and firn properties and airsnow transport processes at Summit, Greenland, Atmos. Environ. 36(15-16), 2789-2797.

Albert, M. R., A. M. Grannas, J. W. Bottenheim, P. B. Shepson, and F. E. Perron (2002), Processes and properties of snow-air transfer in the high Arctic with application to interstitial ozone at Alert, Canada, Atmos. Environ., 36(15-16), 2779-2787.

Alley, R. B., E. S. Salzmann, K. M. Cuffey, and J. J. Fitzpatrick (1990), Summertime formation of depth hoar in central Greenland, Geophys. Res. Lett., 17(12), 2393-2396.

Alley, R. B., et al. (1997), Visual-stratigraphic dating of the GISP2 ice core: Basis, reproducibility, and application, J. Geophys. Res., 102(C12), $26,367-26,381$. 
Arons, E. M. (1994), Dependence of snow thermal and electrical conductivities on microstructure, Ph.D. thesis, Dartmouth Coll., Hanover, N. H.

Arons, E. M., and S. C. Colbeck (1995), Geometry of heat and mass transfer in dry snow: A review of theory and experiment, Rev. Geophys., 33(4), 463-493.

Bartelt, P. B., and M. Lehning (2002), A physical SNOWPACK model for avalanche warning services. Part I: Numerical model, Cold Reg. Sci. Technol., 35(3), 123-145.

Bottenheim, J. W., J. E. Dibb, R. E. Honrath, and P. B. Shepson (2002), An introduction to the ALERT 2000 and SUMMIT 2000 Arctic research studies, Atmos. Environ., 36(15-16), 2467-2469.

Brandt, R. E., and S. G. Warren (1993), Solar-heating rates and temperature profiles in Antarctic snow and ice, J. Glaciol., 39(131), 99-110.

Brandt, R. E., and S. G. Warren (1997), Temperature measurements and heat transfer in near-surface snow at the South Pole, J. Glaciol., 43(144), $339-351$.

Colbeck, S. (1989a), Air movement in snow due to windpumping, J. Glaciol., 35(120), 209-213.

Colbeck, S. C. (1989b), Snow-crystal growth with varying surface temperatures and radiation penetration, J. Glaciol., 35(119), 23-29.

Colbeck, S. C. (1997), Model of windpumping for layered snow, J. Glaciol., 43(143), 60-65.

Cullen, N. J., and K. Steffen (2001), Unstable near-surface boundary conditions in summer on the top of the Greenland ice sheet, Geophys. Res. Lett., 28(23), 4491-4493.

Cullen, N. J., K. Steffen, and P. D. Blanken (2006), Nonstationarity of turbulent heat fluxes at Summit, Greenland, Boundary Layer Meteorol., 122(2), 439-455.

Dadic, R. (2004), High resolution snow stratigraphy and energy balance: Field studies and numerical simulation of snow temperatuers at Summit, Greenland, M.Sc. thesis, ETH Zürich, Zürich, Switzerland.

Dibb, J. E., and M. Fahnestock (2004), Snow accumulation, surface height change, and firn densification at Summit, Greenland: Insights from 2 years of in situ observation, J. Geophys. Res., 109, D24113, doi:10.1029/2003JD004300.

Dibb, J. E., and J. L. Jaffrezo (1997), Air-snow exchange investigations at Summit, Greenland: An overview, J. Geophys. Res., 102(C12), 26,795-26,807.

Dominé, F., and P. B. Shepson (2002), Air-snow interactions and atmospheric chemistry, Science, 297(5586), 1506-1510.

German, R. (1996), Sintering Theory and Practice, John Wiley, New York.

Hutterli, M. A., R. Röthlisberger, and R. C. Bales (1999), Atmosphere-tosnow-to-firn transfer studies of HCHO at Summit, Greenland, Geophys. Res. Lett., 26(12), 1691-1694.

Hutterli, M. A., J. R. McConnell, R. C. Bales, and R. W. Stewart (2003), Sensitivity of hydrogen peroxide $\left(\mathrm{H}_{2} \mathrm{O}_{2}\right)$ and formaldehyde $(\mathrm{HCHO})$ preservation in snow to changing environmental conditions: Implications for ice core records, J. Geophys. Res., 108(D1), 4023, doi:10.1029/ 2002JD002528.

Hutterli, M. A., J. R. McConnell, G. Chen, R. C. Bales, D. D. Davis, and D. H. Lenschow (2004), Formaldehyde and hydrogen peroxide in air, snow and interstitial air at South Pole, Atmos. Environ., 38(32), $5439-5450$

Johnson, J. B., and M. Schneebeli (1999), Characterizing the microstructura and micromechanical properties of snow, Cold Reg. Sci. Technol. $30(1-3)$, 91-100.

Kaempfer, T. U., M. Schneebeli, and S. A. Sokratov (2005), A microstructural approach to model heat transfer in snow, Geophys. Res. Lett., 32, L21503, doi:10.1029/2005GL023873.

Lehning, M., P. Bartelt, B. Brown, C. Fierz, and P. Satyawali (2002a), A physical SNOWPACK model for the Swiss avalanche warning. Part II: Snow microstructure, Cold Reg. Sci. Technol., 35(3), 147-167.
Lehning, M., P. Bartelt, B. Brown, and C. Fierz (2002b), A physical SNOWPACK model for avalanche warning. Part III: Meteorological forcing, thin layer formation and evaluation, Cold Reg. Sci. Technol., 35(3), $169-184$.

McConnell, J. R., R. C. Bales, R. W. Stewart, A. M. Thompson, M. R. Albert, and R. Ramos (1998), Physically based modeling of atmosphereto-firn transfer of $\mathrm{H}_{2} \mathrm{O}_{2}$ at South Pole, J. Geophys. Res., 103(D9), $10,561-10,570$

Ohmura, A. (2001), Summit Greenland Environment Observatory, Mem. Natl. Inst. Polar Res. Spec. Issue Jpn., 54, 153-159.

Ohmura, A., T. Konzelmann, M. Rotach, J. Forrer, M. Wild, A. Abe-Ouchi, and H. Toritani (1994), Energy balance for the Greenland ice sheet: Observation and model computation, IAHS Publ., 223, 85-94.

Ohmura, A., et al. (1998), Baseline Surface Radiation Network (BSRN/ WCRP): New precision radiometry for climate research, Bull. Am. Meteorol. Soc., 79(10), 2115-2136.

Pielmeier, C., and M. Schneebeli (2003), Stratigraphy and changes in hardness of snow measured by hand, ramsonde and snow micro penetrometer: A comparison with planar sections, Cold Reg. Sci. Technol., 37(3), 393-405.

Putnins, P. (1970), Climate of Greenland, in Climates of the Polar Regions, World Surv. Climatol., vol. 14, edited by S. Orvig, pp. 3-113, Elsevier, New York.

Schneebeli, M. (1999), High resolution penetrometery in the high-porosity material snow, paper presented at International Workshop on Penetrometry in the Solar System, Oesterr. Akad. der Wiss., Graz, Austria.

Schneebeli, M., and J. B. Johnson (1998), A constant speed penetrometer for high-resolution snow stratigraphy, Ann. Glaciol., 26, 107-111.

Schneebeli, M., and S. A. Sokratov (2004), Tomography of temperature gradient metamorphism of snow and associated changes in heat conductivity, Hydrol. Processes, 18, 3655-3665.

Schneebeli, M., C. Pielmeier, and J. B. Johnson (1999), Measuring snow microstructure and hardness using a high resolution penetrometer, Cold Reg. Sci. Technol., 30(1-3), 101-114.

Shapiro, L. H., J. B. Johnson, M. Sturm, and G. L. Blaisdell (1997), Snow mechanics-Review of state of knowledge and applications, Tech. Rep. 97-3, Cold Reg. Res. Eng. Lab., Hanover, N. H.

Sturm, M., and C. Benson (2004), Scales of spatial heterogeneity for perennial and seasonal snow layers, Ann. Glaciol., 38, 253-260.

Sturm, M., J. Holmgren, M. König, and K. Morris (1997), The thermal conductivity of seasonal snow, J. Glaciol., 43(143), 26-41.

Sturm, M., D. K. Perovich, and J. Holmgren (2002), Thermal conductivity and heat transfer through the snow on the ice of the Beaufort Sea, J. Geophys. Res., 107(C21), 8043, doi:10.1029/2000JC000409.

Sturm, M., J. B. Johnson, and J. Holmgren (2004), Variations in the mechanical properties of Arctic and subarctic snow at local $(1-\mathrm{m})$ to regional (100-km) scales, paper presented at International Symposium on Snow Monitoring and Avalanches, Snow and Avalanche Study Estab., Manali, India, 12-16 April. (Available at http://www.crrel.usace.army.mil/sid/ sturm/pdfs/SturmISSM2004.pdf)

R. Dadic, Institute of Environmental Engineering, ETH Zürich, CH-8092 Zürich, Switzerland. (dadic@ifu.baug.ethz.ch)

M. A. Hutterli, British Antarctic Survey, Cambridge CB3 0ET, UK.

M. Lehning and M. Schneebeli, WSL Swiss Federal Institute for Snow and Avalanche Research, Flüelastrasse 11, Davos CH-7260, Switzerland. (schneebeli@slf.ch)

A. Ohmura, Institute for Atmospheric and Climate Science, ETH Zürich, CH-8092 Zürich, Switzerland. 